\title{
Are electronic health records ready for genomic medicine?
}

\author{
Maren T. Scheuner, MD, MPH ${ }^{I}$, Han de Vries, $M S^{I}$, Benjamin Kim, MD ${ }^{1,4}$, Robin C. Meili, MBA ${ }^{1}$, \\ Sarah H. Olmstead, $M S^{I}$, and Stephanie Teleki, $P h D^{I}$
}

\begin{abstract}
Purpose: The goal of this project was to assess genetic/genomic content in electronic health records. Methods: Semistructured interviews were conducted with key informants. Questions addressed documentation, organization, display, decision support and security of family history and genetic test information, and challenges and opportunities relating to integrating genetic/genomics content in electronic health records. Results: There were 56 participants: 10 electronic health record specialists, 18 primary care clinicians, 16 medical geneticists, and 12 genetic counselors. Few clinicians felt their electronic record met their current genetic/genomic medicine needs. Barriers to integration were mostly related to problems with family history data collection, documentation, and organization. Lack of demand for genetics content and privacy concerns were also mentioned as challenges. Data elements and functionality requirements that clinicians see include: pedigree drawing; clinical decision support for familial risk assessment and genetic testing indications; a patient portal for patient-entered data; and standards for data elements, terminology, structure, interoperability, and clinical decision support rules. Although most said that there is little impact of genetics/genomics on electronic records today, many stated genetics/ genomics would be a driver of content in the next 5-10 years. Conclusions: Electronic health records have the potential to enable clinical integration of genetic/genomic medicine and improve delivery of personalized health care; however, structured and standardized data elements and functionality requirements are needed. Genet Med 2009:11(7):510-517.
\end{abstract}

Key Words: electronic health records, family history, genetic tests

G enomic discoveries are occurring at an exponential rate. Translation of these discoveries into genetic testing technologies and services for both rare and common diseases has also increased. Providing such personalized information to patients may facilitate shared decision making between patients and physicians, allowing for selection of prevention and disease management options that are tailored to patients' needs and preferences. This approach may ultimately lead to improved health outcomes through risk-appropriate screening, earlier and more accurate diagnosis, and targeted therapies that optimize response and avoid adverse drug reactions. Thus, genetic infor-

From the ${ }^{1}$ RAND Corporation, Santa Monica, California; ${ }^{2}$ Center of Excellence for the Study of Healthcare Provider Behavior, VA Greater Los Angeles Healthcare System, Sepulveda, California; ${ }^{3}$ Department of Health Services, UCLA School of Public Health, Los Angeles, California; and ${ }^{4}$ Division of Hematology-Oncology, UCLA David Geffen School of Medicine, Los Angeles, California.

Maren T. Scheuner, MD, MPH, RAND Corporation, 1776 Main Street, P.O. Box 2138, Santa Monica, CA 90407-2138. E-mail: Scheuner@rand.org.

Disclosure: The authors declare no conflict of interest

Submitted for publication January 15, 2009

Accepted for publication March 6, 2009

Published online ahead of print May 27, 2009.

DOI: 10.1097/GIM.0b013e3181a53331 mation has the potential to not only radically change the way personal health care is delivered but also how public health is maintained and realized.

However, a recent review of the literature has found that clinicians are not prepared to integrate genetic information into routine clinical practice, including collection, documentation, and interpretation of family history for risk assessment and recommendation of risk-specific interventions, and knowing when to offer genetic tests. ${ }^{1}$ Experts believe that electronic health records (EHRs) could enable adoption of genetic information into clinical practice, including the effective use of family history and genetic testing, through the standardization of data collection and organization, and the ability to educate clinicians about evidence-based use of such information at the point of care with clinical decision support. ${ }^{2,3}$

The goal of this project was to gain an in-depth understanding of the state of the art in EHR products regarding documentation and organization of family history and genetic test information, related clinical decision support, and the needs and interests of key stakeholders regarding genetics/genomics content in EHRs.

\section{METHODS}

\section{Study population and sampling strategy}

Four key stakeholder groups were identified for this study including primary care clinicians (family practice physicians and general internists), medical geneticists (board-certified MDs and $\mathrm{PhDs}$ specializing in genetics), genetic counselors (boardcertified professionals with Master's degrees in genetic counseling), and EHR representatives (senior management of companies marketing commercial EHR products and health information specialists or managers of EHR products developed within a health system).

A convenience sampling strategy was used. Potential participants were identified through email listservs of their respective professional societies (Table 1). We asked the administrators of these listservs to send an email to their respective members notifying them of the opportunity to participate in a research project addressing genetics/genomics content in EHRs. Those who were interested were asked to respond to the principal investigator (M.T.S.) by email. In return, a letter was sent by email describing the purpose of the study, along with a list of the study questions to be discussed. An interview was scheduled with interested respondents. Clinicians were excluded if they were not from a stakeholder group or did not use an EHR, and EHR representatives were excluded if they did not provide an ambulatory or inpatient EHR product.

We sought to complete enough interviews in each stakeholder group so as to be able to identify clear themes, without collecting overly repetitive information. As few as 5-10 participants will allow a skilled qualitative researcher to elucidate core issues about a particular phenomenon. ${ }^{4}$ Thus, we aimed to interview eight or nine participants in each of the four stakeholder groups. 
Table 1. Response rates of stakeholder groups

\begin{tabular}{llcc}
\hline $\begin{array}{l}\text { Stakeholder } \\
\text { groups }\end{array}$ & \multicolumn{1}{c}{$\begin{array}{c}\text { Listservs } \\
\text { contacted }\end{array}$} & $\begin{array}{c}\text { Estimated No. } \\
\text { listserv } \\
\text { participants }\end{array}$ & $\begin{array}{c}\text { No. } \\
\text { respondents }\end{array}$ \\
\hline $\begin{array}{l}\text { EHR } \\
\text { representatives }\end{array}$ & $\begin{array}{c}\text { EHRVA } \\
\text { members }\end{array}$ & 43 & $13^{a}$ \\
& $\begin{array}{c}\text { HL7 Clinical } \\
\text { genomics SIG }\end{array}$ & 10 & \\
Primary care & AAFP CHIT & 1,070 & 18 \\
& $\begin{array}{l}\text { SGIM genetics in } \\
\text { primary care }\end{array}$ & 28 & \\
& SIG & & \\
& STFM genetics & 20 & \\
& SIG & & \\
Medical & ACMG members & 1,300 & 16 \\
geneticists & NSGC Genetic & 42 & 12 \\
Genetic & Services & & \\
Counselors & Committee & &
\end{tabular}

${ }^{a}$ Three EHR representatives were from one health system with an internally developed EHR, and two representatives worked for the same commercial EHR vendor. To avoid double counting of the responses of the EHR representatives regarding description of their EHR products, for our analyses we combined the responses of subjects from the same organization, thereby consolidating our sample size to 10 EHR representatives. These individuals represented eight commercial EHR vendors and two health systems.

AAFP, American Academy of Family Practice; ACMG, American College of Medical Genetics; CHIT, computerized health information technology; EHR, electronic health record; EHRVA, Electronic Health Record Vendors Association; HL7, Health Level 7; NSGC, National Society of Genetic Counselors; SIG, special interest group; SGIM, Society of General Internal Medicine; STFM, Society of Teachers of Family Medicine.

\section{Data collection}

A semistructured interview guide was developed based on our research objectives, a review of the literature regarding issues relating to use of family history and genetic tests in clinical practice, review of leading EHR products, and our own experience. The interview guide was pilot tested with four individuals. Based on their feedback, the guide was refined to ensure that the questions were clear and could be covered in a 60-minute interview. The interview guide included sections entitled "genetics/genomics content" and "genetics/genomics issues" and consisted of questions addressing the following domains: documentation, organization, display, decision support, and security for family history data in the EHR (six questions); ordering, results, decision support and security for genetic tests in the EHR (four questions); and challenges and opportunities relating to integration of genetics/genomics content in the EHR (two questions), and the current and future impact of genetic/genomic medicine on health information technology (IT) and EHR products and vice versa (two questions) (Table 2).

Using the interview guide, one investigator (M.T.S.) conducted the semistructured interviews (the majority by telephone) from December 2006 to May 2007. Our interview guide allowed for the interviewer to ask questions in whatever order seemed most appropriate and natural during the conversation. The interviewer was also free to paraphrase questions, to probe each interviewee in different ways as relevant to the given responses, and we allowed for and encouraged tangents in the
Table 2. Core questions asked of stakeholder groups

Genetics/genomics content-family history

Does your EHR include family history information?

How is family history documented (e.g., text, structured format)?

How is family history data entered (by whom)?

How is family history data displayed (e.g., text field, graph, pedigree drawing)?

Is there clinical decision support for familial risk assessment/pedigree analysis?

Is security or access permission different for family history?

Genetics/genomics content-genetic test orders and results

Does your EHR include genetic test orders and results?

Are genetic test orders handled in a way that is different from other laboratory tests?

Is there clinical decision support for test ordering or interpretation?

Is security or access permission different for genetic tests?

Genetics/genomics issues

What are the barriers or challenges, if any, to including family history and genetic test information in EHRs?

(EHR representatives only) How has the market reacted to the increasing discussion of genetic/genomic medicine and has this translated to changes in data input or other requirements?

(Clinicians only) Have EHR vendors/product managers responded to your genetic/genomic medicine needs, and what data elements or functionality would be most useful?

What is the impact of EHRs and health information technology on genetic/genomic medicine, and how do you see that changing over the next 5 to 10 years?

What is the impact of genetic/genomic medicine on EHRs and health information technology, and how do you see that changing over the next 5 to 10 years?

Respondents described a variety of genetic tests including cytogenetic, biochemical, and molecular single gene and multiplex tests.

EHR, electronic health record.

conversation and the pursuit of different subtopics as appropriate given each interviewee's responses and individual experiences. When needed, definitions of terms and examples were provided during the interviews to convey the key concept underlying each question. The interviews were recorded and transcribed.

\section{Data analysis}

Using the transcribed interviews, two investigators (H.D.V., M.T.S.) independently developed codes that represented key themes found in the participants' responses by examining each response to each question and developing phrases or terms that best represented key concepts. A final set of codes was defined after reconciliation of differences. This set of codes was applied to the interview transcripts by two independent coders (B.K., S.H.O.) trained in the relevant topics of family history, genetic tests, and EHRs. Discrepancies in coding of the transcripts were reconciled by the coders, and when necessary other study investigators (M.T.S., H.D.V.). The codes were comprehensive with very few responses that did not match at least one of the coding options. Every question also had response options of "don't know" and 
"missing/not answered/other." The latter was coded if the respondent did not give a response at all or gave a response that did not address the questions they were asked and for which a code did not exist. The coded responses were entered into a database and parsed to produce reports on a given topic sorted by stakeholder group. The resulting final set of coded responses was used to calculate descriptive statistics for all participants and stratified by stakeholder group.

To measure coding reliability, we estimated a pooled kappa statistic using the codes initially assigned by the coders to each transcript. The pooled kappa statistic efficiently summarizes Cohen's kappa ${ }^{5}$ across a large number of questions, and is described elsewhere in more detail. ${ }^{6}$ We estimated pooled kappa across all questions as 0.63 , which can be qualified as "substantial" reliability, according to the classification proposed by Landis and Koch.7

The RAND Human Subjects Protection Committee approved the study protocol including the plans for data collection and analysis.

\section{RESULTS}

There were 59 eligible subjects including 18 primary care clinicians, 16 medical geneticists, 12 genetic counselors, and 13 EHR representatives. The EHR representatives included five chief medical officers, one chief executive/medical officer, three product managers, and four IT specialists. To avoid double counting of the responses of the EHR representatives regarding description of their EHR products, for our analyses we combined the responses of subjects from the same organization, thereby consolidating our sample size to 10 EHR representatives. These individuals represented eight commercial EHR vendors and two health systems, among which there were two large $(>20,000$ EHR users), three medium (10,000-20,000 EHR users), and five small ( $<10,000$ EHR users) organizations.

Characteristics of the clinician participants are shown in Table 3. A large proportion of each clinician group spent more than $50 \%$ of their time providing patient care. Half of the medical geneticists, $25 \%$ of the genetic counselors, and $22 \%$ of the primary care clinicians used an internally developed EHR. The others most commonly used were Epic, General Electric, and Cerner EHR products.

\section{Family history}

Of the 56 respondents, all but three (two medical geneticists and one genetic counselor) indicated family history documentation was included in their EHR. Most (96\%) of the 53 participants who could enter family history data stated that it could be documented in a nonstructured format, usually by using a text box somewhere in the clinic record. Two thirds of these respondents said family history could also be documented using a structured format. Among the 35 respondents who could enter structured data, 19 (54\%) stated data regarding specific family members and their disease history was captured, and another four $(11 \%)$ indicated the structure was limited to "family history of .. Yet, even with the option of structured family history data documentation, the general sentiment was that text entry was preferable.

Documentation of family history within the EHR was performed most often by the physician $(81 \%)$, followed by other staff $(42 \%)$, or by patients electronically using a patient portal or personal health record (PHR) (11\%). Although patient-provided data were appealing to most, there were concerns about the quality of patient-entered data and technical impediments to sharing of the family history data between the PHR and EHR.
Table 3. Characteristics of clinician respondents

\begin{tabular}{ccc}
\hline Primary & Medical & Genetic \\
Care, ${ }^{a} \%$ & geneticists, ${ }^{b} \%$ & counselors, ${ }^{c} \%$ \\
$(N=18)$ & $(N=16)$ & $(N=12)$ \\
\hline
\end{tabular}

Setting

$\begin{array}{lrrr}\text { Academics } & 44^{d} & 68^{e} & 25 \\ \text { Group practice } & 39 & 13 & 33^{f} \\ \text { Solo practice } & 11 & 0 & 0 \\ \begin{array}{l}\text { HMO/integrated } \\ \quad \text { system }\end{array} & 6 & 6 & 25 \\ \text { State/federal agency } & 0 & 13 & 17\end{array}$

$\%$ of time providing patient care

Less than 25

28

13

25

25 to 49

33

37

50 or more

39

50

58

Years in practice

Less than 10

13

41

10-19

44

37

20 or more

Not answered

EHR type

$\begin{array}{lccr}\text { Internally developed } & 22 & 50 & 25 \\ \text { GE centricity } & 27 & 13 & 8 \\ \text { Epic } & 22 & 25^{g} & 42 \\ \text { Practice partner } & 11 & 0 & 0 \\ \text { All scripts } & 6 & 6^{h} & 0 \\ \text { Cerner } & 0 & 6^{i} & 17 \\ \text { Ecclypsis } & 0 & 0 & 8 \\ \text { SOAPware } & 6 & 0 & 0 \\ \text { Oasis } & 6 & 0 & 0\end{array}$

PHR

$\begin{array}{llll}\text { Yes } & 11 & 44 & 67\end{array}$

No $\quad 83 \quad 56 \quad 33$

Do not know

60

0

${ }^{a}$ Among primary care physicians, there were 11 family practice physicians and seven general internists. Other areas of specialty included education (1), informatics (3), pediatrics (2) psychiatry (1), health services research (1), and hospitalist (1).

${ }^{b}$ Among medical geneticists, other area of specialty included pediatrics (8), adult medicine (6), cytogenetics (2), and obstetrics and gynecology (1).

${ }^{c}$ Among genetic counselors, areas of specialty included general (4), adult/cancer (3), prenatal (2), public health (1), cancer (1), and ophthalmology (1).

${ }^{d}$ Other setting: academic (1).

${ }^{e}$ Other setting: commercial laboratory (1), group practice (1).

${ }^{f}$ Other setting: community hospital (3).

${ }^{g}$ In combination with: Cerner (1), Ecclypsis (1)

${ }^{h}$ In combination with: Phillips (1).

${ }^{i}$ In combination with: MEGIS (1).

${ }^{j}$ In combination with: internally-developed (1). 
About half of respondents (53\%) stated that a specific section or "tab" was designated for family history capture; however, a substantial proportion $(40 \%)$ indicated that there was no special section for family history within the EHR and that it was mostly found within the clinic note documenting a specific patient encounter. None of the respondents described the inherent capability of their EHR to generate a pedigree drawing from the entered family history data, and none used pedigree drawing software that could interface with their EHR. Two medical geneticists and one genetic counselor (7\% of clinician respondents) used pedigree drawing software but generally did not scan pedigrees into their EHR. Four medical geneticists, three genetic counselors, and two primary care clinicians $(21 \%$ of clinician respondents) drew pedigrees or "genograms" by hand, which were subsequently scanned into the EHR.

Generally, clinical decision support that assessed familial risk or provided alerts regarding management based on family history was lacking. Only one EHR representative indicated current availability of clinical decision support relating to the family history stating, "Within our template system, if you say premature family history of whatever condition, there are clinical reminders that will ask you to maybe check something else." Two EHR representatives, one primary care clinician and one medical geneticist ( $8 \%$ of respondents) indicated that family history of a condition would populate the problem list in the EHR. Three EHR representatives, three medical geneticists, and one genetic counselor ( $13 \%$ of respondents) stated that clinical decision support for family history should be possible through customization of their product.

All of the EHR representatives who provided a response ( $90 \%$ of this group) to a question about security and access to family history said family history was handled in a manner similar to other medical information. Two primary care clinicians, three geneticists, and one counselor (14\% of clinicians) said family history was treated differently, and one primary care clinician, three geneticists, and two counselors (14\% of clinicians) said access to family history data were limited to certain personnel. The genetics professionals made comments suggesting the need for greater security of family history information, particularly to protect privacy of family members regarding their health information. One of the primary care clinicians recognized protections relating to family history afforded by the Health Insurance Portability and Accountability Act.

\section{Genetic test orders and results}

When asked whether genetic test orders were handled differently by their EHR, $77 \%$ of the 56 participants provided a response; there were two (4\%) do not know and $11(20 \%)$ missing/not answered/other responses, which included respondents who could not order laboratory tests with the EHR. Fourteen $(25 \%)$ participants who could order laboratory tests with their EHR could not order genetics tests, whereas $18(32 \%)$ said genetic tests could be ordered; yet, $11(20 \%)$ stated that these tests were ordered as miscellaneous tests that were typed into a text box or written on paper and then scanned into the EHR. Only 4\% said all genetic tests could be found in their test order menu, and $14 \%$ said some genetic tests were in the test order menu. Five geneticists said that some or all of their genetic tests were ordered using paper forms, and one medical geneticist said genetic tests were ordered on paper as research tests and the orders were not entered into the EHR. The scope of genetic tests mentioned as examples by our respondents ranged from cytogenetic, biochemical and molecular tests, both single gene and multiplex. Genetics professionals were more likely to comment on all of the above, whereas primary care clinicians typically provided examples of common single gene disorders.

When participants were asked about the availability of clinical decision support relating to genetic test ordering or results in their EHR, only two (4\%) participants - both genetics professionals - reported that they had access to this type of support. One medical geneticist described this decision support as the ability to track laboratory results, and a genetic counselor described an alert relating to certain genetic test results specific to obstetrics and gynecology practice.

When asked about security of genetic test results in the EHR, 35 participants $(63 \%)$ said they were treated the same as other laboratory tests, and eight (14\%) said genetic test results were treated differently. Sometimes this difference related to the process of ordering genetic tests, sample handling, or how or where orders and results were documented in the EHR, whereas other responses indicated concerns about the privacy of the genetic tests results.

Several genetics professionals described security and access permission requirements relating to genetic test results in their EHRs. A medical geneticist described how an audit trail was established for some genetic tests but not all. A genetic counselor mentioned a state law that required different handling of genetic test results and that patients had to sign a specific release of information indicating whether the results could be disclosed to the referring clinician or the patient's insurance company. Another genetic counselor described a similar policy stating that genetic test results were not entered into the electronic medical record until the patient was informed of the results. Another genetic counselor stated that certain genetic test results, such as results for Huntington disease and hereditary breast and ovarian cancers, were not scanned into the EHR to protect patient privacy. There were seven (13\%) participants who said access to genetic test results was limited to certain personnel.

\section{Challenges and opportunities relating to genetics/ genomics content in EHRs}

Table 4 shows the frequencies of responses to a question about the barriers or challenges, if any, to including family history and genetic test result information in EHR products. Of the 20 coded responses, most related to family history data collection, documentation, storage, or display. The time and resources required to enter family history data were a particular concern for primary care providers. Ethical issues including privacy concerns, genetic discrimination, and clinicians' duty to warn at-risk relatives were mentioned by almost a third of respondents as a challenge or barrier; however, most of these responses came from genetic counselors. Genetics professionals most often identified lack of pedigree drawing capabilities or difficulty interfacing proprietary pedigree drawing programs with EHRs as challenges. Only one respondent stated there were no barriers or challenges.

Of the 46 clinicians interviewed, 27 (59\%) provided responses to a question asking whether their genetic/genomic medicine needs had been met by their EHR vendor or IT specialist. The majority (74\%) of respondents, including eight primary care clinicians, eight geneticists, and four genetic counselors, felt that these needs had not been met, with almost half stating that this was because of "limited to no demand from health care providers" or because "genetics is a low priority." Only two (4\%) clinicians said their EHR vendor or IT specialist had responded to their genetic/genomic medicine needs, two (4\%) said EHR administrators were beginning to meet their needs, and three (5\%) said they needed to work with their vendor/IT specialist to have their needs met. 
Table 4. Barriers and challenges relating to the integration of genetics/genomics content into the EHR

\begin{tabular}{|c|c|c|c|c|c|}
\hline Response & $\begin{array}{l}\text { Total, \% } \\
(n=56)\end{array}$ & $\begin{array}{l}\text { EHR } \\
\text { repre-sentatives, \% } \\
(n=10)\end{array}$ & $\begin{array}{l}\text { Primary care, } \% \\
\quad(n=18)\end{array}$ & $\begin{array}{l}\text { Medical } \\
\text { geneticists, \% } \\
(n=16)\end{array}$ & $\begin{array}{l}\text { Genetic } \\
\text { counselors, \% } \\
(n=12)\end{array}$ \\
\hline $\begin{array}{l}\text { Time and resources required to enter family history, } \\
\text { interrupts workflow, and lack of reimbursement to } \\
\text { gather and input family history }\end{array}$ & 55 & 30 & 78 & 56 & 42 \\
\hline $\begin{array}{l}\text { Getting complete and accurate family history, concerns } \\
\text { about patient-entered data, and reconciling } \\
\text { conflicting family history }\end{array}$ & 39 & 50 & 22 & 50 & 42 \\
\hline Clinicians do not understand how to use family history & 30 & 30 & 39 & 25 & 25 \\
\hline $\begin{array}{l}\text { Privacy concerns, concerns regarding genetic } \\
\text { discrimination, and duty to warn at-risk relatives }\end{array}$ & 29 & 10 & 6 & 25 & 83 \\
\hline Lack of demand for genetics content in EHRs & 25 & 40 & 33 & 13 & 17 \\
\hline $\begin{array}{l}\text { Lack of pedigree drawing capability or difficulty } \\
\text { interfacing proprietary pedigree drawing programs } \\
\text { with the EHR }\end{array}$ & 25 & 20 & 6 & 31 & 50 \\
\hline $\begin{array}{l}\text { Lack of standards for data elements, terminology, } \\
\text { structure, interoperability, and clinical decision } \\
\text { support rules }\end{array}$ & 21 & 30 & 22 & 25 & 8 \\
\hline $\begin{array}{l}\text { Ensuring adequate security of the data and determining } \\
\text { access permission }\end{array}$ & 21 & 10 & 11 & 13 & 58 \\
\hline $\begin{array}{l}\text { A minority of patients take advantage of the patient } \\
\text { portal, which could be used for family history data } \\
\text { entry }\end{array}$ & 18 & 20 & 6 & 38 & 8 \\
\hline $\begin{array}{l}\text { Lack of incentives (e.g., from federal government, } \\
\text { reimbursement); if they existed this would facilitate } \\
\text { inclusion of genetics }\end{array}$ & 18 & 0 & 33 & 19 & 8 \\
\hline $\begin{array}{l}\text { Lack of available clinical decision support (e.g., for } \\
\text { family history risk assessment, genetic test ordering, } \\
\text { drug-gene interaction) }\end{array}$ & 16 & 0 & 17 & 31 & 8 \\
\hline $\begin{array}{l}\text { Limited adoption of the EHR (includes "technology } \\
\text { phobia") }\end{array}$ & 16 & 10 & 11 & 31 & 8 \\
\hline Presenting genetic test results in a meaningful way & 13 & 40 & 11 & 6 & 0 \\
\hline $\begin{array}{l}\text { Preferences and requirements for family history } \\
\text { documentation vary by different specialists, and } \\
\text { "ownership" of the family history in the EHR is } \\
\text { unclear }\end{array}$ & 9 & 10 & 0 & 6 & 25 \\
\hline $\begin{array}{l}\text { Lack of interface between laboratory information } \\
\text { systems and EHR products }\end{array}$ & 7 & 20 & 6 & 6 & 0 \\
\hline $\begin{array}{l}\text { Difficult to find genetic information (family history or } \\
\text { genetic test results) in the EHR }\end{array}$ & 4 & 0 & 6 & 6 & 0 \\
\hline $\begin{array}{l}\text { Inability to link medical records across persons in } \\
\text { same family }\end{array}$ & 4 & 10 & 0 & 0 & 8 \\
\hline $\begin{array}{l}\text { Lack of functionality relating to family history } \\
\text { documentation (e.g., unable to know who has } \\
\text { entered the family history, cannot easily update } \\
\text { family history, cannot indicate whether the history } \\
\text { was verified) }\end{array}$ & 4 & 0 & 0 & 13 & 0 \\
\hline $\begin{array}{l}\text { Genetic test results are not typical laboratory tests (i.e., } \\
\text { genetic tests should be handled differently because } \\
\text { they are complex and persistent data) }\end{array}$ & 4 & 20 & 0 & 0 & 0 \\
\hline No barriers or challenges & 2 & 0 & 6 & 0 & 0 \\
\hline
\end{tabular}

EHR, electronic health record.

Participants could provide more than one response. There were no "don't know" or "not answered/missing/other responses". 
Table 5. EHR data elements or functionality relating to genetics/genomics that would be useful to clinicians

\begin{tabular}{|c|c|c|c|c|}
\hline Response & $\begin{array}{l}\text { All clinicians, } \% \\
\quad(n=46)\end{array}$ & $\begin{array}{l}\text { Primary care, } \% \\
\quad(n=18)\end{array}$ & $\begin{array}{l}\text { Medical } \\
\text { geneticists, \% } \\
(n=16)\end{array}$ & $\begin{array}{l}\text { Genetic } \\
\text { counselors, \% } \\
(n=12)\end{array}$ \\
\hline Pedigree drawing capabilities & 46 & 44 & 50 & 42 \\
\hline $\begin{array}{l}\text { Clinical decision support for referential information, } \\
\text { familial risk assessment, referral to genetics, genetic test } \\
\text { orders and interpretation, or drug prescribing }\end{array}$ & 39 & 61 & 38 & 8 \\
\hline Patient portal/patient-entered data & 24 & 33 & 25 & 8 \\
\hline $\begin{array}{l}\text { Standards for data elements, terminology, structure, } \\
\text { interoperability, and clinical decision support rules }\end{array}$ & 22 & 33 & 13 & 17 \\
\hline $\begin{array}{l}\text { Family history better organized and more accessible (e.g., } \\
\text { in one place in EHR) }\end{array}$ & 20 & 22 & 13 & 25 \\
\hline Ability to update the family history in the EHR & 17 & 17 & 13 & 25 \\
\hline Genetic tests better organized and accessible & 17 & 22 & 0 & 33 \\
\hline $\begin{array}{l}\text { Structured (detailed or granular) data format rather than } \\
\text { text-only for clinical decision support and data queries }\end{array}$ & 15 & 22 & 6 & 17 \\
\hline Ability to limit access permission (privacy concerns raised) & 13 & 11 & 19 & 8 \\
\hline $\begin{array}{l}\text { Efficient (branching, algorithmic, user-friendly) and } \\
\text { flexible way (e.g., targeted or comprehensive) to enter } \\
\text { and/or display family history }\end{array}$ & 13 & 17 & 13 & 8 \\
\hline $\begin{array}{l}\text { Ability to migrate/integrate medical or family history } \\
\text { among EHRs of different family members }\end{array}$ & 11 & 6 & 13 & 17 \\
\hline Reminding or requiring user to complete the family history & 9 & 11 & 6 & 8 \\
\hline Do not know & 2 & 0 & 6 & 0 \\
\hline Not answered/missing/other & 15 & 6 & 19 & 25 \\
\hline
\end{tabular}

EHR, electronic health record.

Participants could provide more than one response.

Clinicians were asked about data elements or functionality relating to genetics/genomics that could be useful to them (Table 5). The most frequent responses were pedigree drawing, followed by clinical decision support and a patient portal for patient-entered data. However, the latter two responses were not common among the genetic counselors.

The 10 EHR representatives were asked about the market reaction to the increasing discussion of genetics/genomics and whether this had translated into demands on them for data input or functionality requirements. Many $(60 \%)$ stated that the demands for genetics content were minimal to none, and three indicated that their clients just wanted the "basics" today. Half of the EHR representatives said vendors were trying to improve capture of genetics content, and one said that clients would want better representation of genetic data in the EHR when it was clear that it would improve health outcomes. Three said genetics was or would be a future initiative of their organization; one said their requirements will change to accommodate genetics content and two anticipate government interventions might influence their genetics content requirements.

Only four (7\%) participants indicated there is an impact of genetic/genomic medicine on health IT and EHRs today. However, $41 \%$ said there would be an impact in the next 5-10 years. In describing how genetic/genomic medicine would impact EHRs, 59\% said it would improve several aspects of patient care, including risk assessment, management, prevention, and the ability to provide personalized medicine. In addition, $36 \%$ said that it would change EHRs and would drive EHR content and capabilities as genetic/genomic knowledge increased. Five (9\%) participants, who were all clinicians, also indicated that genetics/genomics would encourage creative development of EHR functionality relating to privacy, security of information, and selective access permission. Only two (4\%) participants, both genetic counselors, thought genetic information might provide commercial gains for the EHR products industry, and one of these counselors voiced concerns that proprietary and commercial interests could limit the integration of genetic information in EHRs.

Only $9 \%$ of the 56 participants thought health IT and EHRs currently had an impact on genetic/genomic medicine, but $36 \%$ thought this industry would have an impact in the next 5-10 years (Table 6). This future impact was most often described as improving the ability to manage genetic information, enabling medical decision making about genetics, facilitating utilization of genetic services, and facilitating genomics research. Six participants, all of whom were genetic counselors, indicated that EHRs would raise ethical concerns regarding genetic information.

\section{DISCUSSION}

Among the clinicians participating in our study, few felt that their EHR met their genetic/genomic medicine needs, mostly because they perceive genetics to be a low priority of EHR 
Table 6. The impact of health information technology and EHRs on genetic/genomic medicine

\begin{tabular}{|c|c|c|c|c|c|}
\hline Response & $\begin{array}{l}\text { Total, \% } \\
(n=56)\end{array}$ & $\begin{array}{l}\text { EHR } \\
\text { representatives, \% } \\
(n=10)\end{array}$ & $\begin{array}{l}\text { Primary } \\
\text { care, } \% \\
(n=18)\end{array}$ & $\begin{array}{l}\text { Medical } \\
\text { geneticists, \% } \\
(n=16)\end{array}$ & $\begin{array}{l}\text { Genetic } \\
\text { counselors, \% } \\
(n=12)\end{array}$ \\
\hline There is an impact & 9 & 10 & 6 & 13 & 8 \\
\hline There is limited to no impact & 11 & 10 & 22 & 6 & 0 \\
\hline There will be an impact in next 5 to 10 years & 36 & 30 & 44 & 25 & 42 \\
\hline $\begin{array}{l}\text { Will improve the ability to manage genetic information (e.g., } \\
\text { improve data capture, display of information, sharing of data, } \\
\text { and/or use of genetic data) }\end{array}$ & 43 & 40 & 28 & 50 & 50 \\
\hline $\begin{array}{l}\text { Will enable clinical decision-making (e.g., risk assessment, referral } \\
\text { to genetics specialist or for genetic testing, treatment and } \\
\text { prevention); Will provide clinicians with knowledge }\end{array}$ & 39 & 30 & 33 & 44 & 42 \\
\hline $\begin{array}{l}\text { Genetics will facilitate uptake/utilization of genetics in practice of } \\
\text { genetics professionals or non-geneticists; genetics will be more } \\
\text { available/accessible }\end{array}$ & 25 & 20 & 17 & 25 & 42 \\
\hline $\begin{array}{l}\text { Genetics/genomics can't be done without EHRs; information } \\
\text { technology is essential/necessary }\end{array}$ & 20 & 40 & 22 & 13 & 8 \\
\hline $\begin{array}{l}\text { Will facilitate genomics research (i.e., our understanding of genetic } \\
\text { basis of disease and/or disease risk, management and treatment); } \\
\text { ambulatory offices will become a source of structured genetic } \\
\text { data }\end{array}$ & 18 & 40 & 11 & 25 & 0 \\
\hline $\begin{array}{l}\text { Will raise ethical concerns around privacy, confidentiality, } \\
\text { discrimination, and duty to warn regarding genetic information }\end{array}$ & 11 & 0 & 0 & 0 & 50 \\
\hline Personal health records will be crucial to genetics/genomic medicine & 2 & 0 & 0 & 0 & 8 \\
\hline Don’t know & 2 & 0 & 6 & 0 & 0 \\
\hline Not answered/Missing/Other & 4 & 20 & 0 & 0 & 0 \\
\hline
\end{tabular}

vendors or the organization (e.g., group practice, academic department) in which they work. The majority (70\%) of EHR representatives echoed this sentiment and said the demand for genetics/genomics content from their clients had been low, and $40 \%$ explained that their clients just wanted the basics at this time. Consequently, few participants thought EHRs had an impact on genetic/genomic medicine now. However, 20\% said genetic/genomic medicine would not be possible without EHRs, and almost half said EHRs would have an impact on genetics/ genomics in the next 5-10 years by enabling management of genetic information, genomics research, and clinical decision making. In considering genetics/genomics impact on EHRs, most participants believed there was little to no impact today, many stated that genetics/genomics would be a driver of EHR content in the next 5-10 years, and the integration of genetics/ genomics in EHRs would improve the ability to provide personalized health care.

The most common EHR data elements and functionality requirements relating to genetics/genomics that the clinicians would find useful include: pedigree drawing; clinical decision support for familial risk assessment or genetic testing indications; a patient portal for patient-entered data; standards for data elements, terminology, structure, interoperability, and clinical decision support rules; and better organization of the family history. Although genetic counselors were less enthusiastic about clinical decision support and a patient portal compared to medical geneticists and primary care clinicians. This wish list reflects the lack of pedigree drawing and clinical decision support capabilities of the EHRs used by our participants, as well as the common challenges to integrating genetics into EHRs, including the time and resources required to gather, document and interpret family history. These challenges were frequently identified by each of the stakeholder groups. However, there were important differences between the groups regarding other items. A majority of genetic counselors identified lack of pedigree drawing, privacy, data security and duty to warn issues as challenges to integration of genetics/genomics content in EHRs, whereas these topics were mentioned as challenges by a minority of the other stakeholder groups. Genetic counselors reported the availability of health information about an individual's relatives in the EHR might pose risks relating to stigmatization or possible discrimination by insurers or employers, both for the patient of record and their family members. These concerns were perhaps compounded by the fact that most EHRs used by those we interviewed did not have special security and access permission requirements for genetic information. In response to these concerns, several clinicians believed that genetic information would encourage creative development of privacy and security measures in the EHR.

The lack of the "basic" and more traditional genetics EHR functionality requirements described by our participants does not bode well for the integration of more complex genomic applications that will become increasingly available and relevant to many more patients in the near future (e.g., whole 
genome sequencing, array technologies, and gene expression profiles). Although these new genomic applications will likely pose additional challenges for EHR developers, our findings relating to traditional genetics requirements remain relevant. ${ }^{8}$

There are several limitations to this study. The sample reflects the perspectives from only four stakeholder groups, and participants were ascertained through convenience sampling. Moreover, the participants were limited to representatives who use email and who are members of a professional society listserv, and for the clinicians, all were using or had recently used an EHR. For the primary care providers, there was additional potential for bias because listservs of special interests groups addressing genetics and EHRs were targeted. Thus, because our participants are already users of EHRs and because many are invested in the field of genetics/genomics, we expect their responses to be more optimistic and demanding than responses we might expect from each of the general stakeholder populations. This might explain some of the comments describing EHRs as essential to the practice of genetics/genomics and in providing personalized health care. Nonetheless, from this selective group of participants, we learned that genetics content in various EHR products is limited and many features are lacking, such as the ability to (1) collect family history in a structured, systematic way, (2) organize and display it in a pedigree format that can be easily updated, (3) order genetic tests (4) organize and display genetic test results, and (5) interpret familial risk and guide genetic test ordering and results interpretation through clinical decision support. Despite these limitations, the uniformity of responses within each stakeholder group is reassuring and suggests that our results are representative.

Another potential limitation was conducting the majority of our interviews by telephone, which does not allow for incorporation of visual cues during the interview that might have influenced the line of questioning. However, telephone interviews allowed us to include participants from all over the country, which would not have been feasible if we conducted only in-person interviews. Moreover, we have found interviews conducted by phone may at times be more effective because the interviewees may be more open to discuss certain topics by phone than during an in-person interview.

\section{CONCLUSIONS}

Genomic information relating to health and disease is increasing exponentially, and this information promises to improve diagnosis, choice of treatments, and disease prevention. ${ }^{9-11}$ Our findings show that key stakeholders believe that EHRs have the potential to facilitate the integration of genetic information into routine clinical practice, which is highly de- sirable given the lack of preparedness regarding genetic/ genomic medicine for the majority of the health care workforce. ${ }^{1}$ However, basic requirements must be addressed by EHR products before they can effectively facilitate adoption of genetic/genomic medicine, including improved documentation, organization, and display of family history; improved documentation and organization for genetic test orders and results; clinical decision support for family history risk assessment and genetic testing indications; and consideration of privacy and security of genetic information.

\section{ACKNOWLEDGMENTS}

This work was funded by the RAND Corporation through an investigator-initiated Independent Research \& Development Grant, and Dr. Kim was supported by a Ruth L. Kirschstein National Research Service Award from the National Institutes of Health (T32 HL 66992). Preliminary results of this work have been presented at a meeting of the Department of Health and Human Services American Health Information Community in February 2008 and a meeting of the American College of Medical Genetics in March 2008. Dr. Scheuner has a patent pending (US Application No. 20060173717) for a familial risk stratification method and apparatus.

\section{REFERENCES}

1. Scheuner MT, Sieverding P, Shekelle PG. Delivery of genomic medicine for common chronic adult diseases. A systematic review. JAMA 2008;299: 1320-1334.

2. Deverka PA, Doksum T, Carlson RJ. Integrating molecular medicine in the U.S. health care system: opportunities, barriers, and policy challenges. Clin Pharmacol Ther 2007;82:427-424.

3. Glaser J, Henley DE, Downing G, Brinner KM; Personalized Health Care Workgroup of the American Health Information Community. Advancing personalized health care through health information technology: an update from the American Health Information Community's Personalized Health Care Workgroup. J Am Med Assoc 2008;15:391-396.

4. Morse JM. Designing funded qualitative research. In: Denzin NK, Lincoln YS, editors. Handbook of qualitative research. Thousand Oaks, CA: Sage Publications, 1994:220-235.

5. Cohen JA. Coefficient of agreement for nominal scales. Education Psychol Measurement 1960;20:37-46.

6. De Vries H, Elliott MN, Kanouse DE, Teleki SS. Using pooled kappa to summarize interrater agreement across many items. Field Methods 2008;20: 272-282.

7. Landis JR, Koch GG. The measurement of observer agreement for categorical data. Biometrics 1977;33:159-174.

8. Guttmacher AE, Collins FS, Carmona RH. The family history-more important than ever. $N$ Engl J Med 2004;351:2333-2336.

9. Scheuner MT, Yoon PW, Khoury MJ. Contribution of Mendelian disorders to common chronic disease: opportunities for recognition, intervention and prevention. Am J Med Genet 2004;125C:50-65.

10. Wattendorf DJ, Hadley DW. Family history: the three-generation pedigree. Am Fam Physician 2005;72:441-448.

11. Feero WG, Guttmacher AE, Collins FS. The genome gets personal-almost. JAMA 2008;299:1351-1352. 